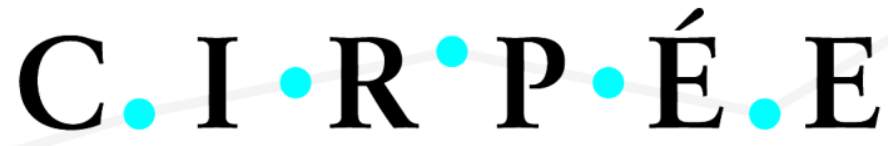

Centre Interuniversitaire sur le Risque, les Politiques Économiques et l'Emploi

Cahier de recherche/Working Paper 12-29

Rural Policies and Poverty in Tanzania: an Agricultural Household Model-Based Assessment

Luca Tiberti

MarcoTiberti

Août/August 2012

Version révisée/Revised : Novembre/November 2012

Luca Tiberti: CIRPÉE \& PEP, Université Laval

luca.tiberti@ecn.ulaval.ca

Marco Tiberti: University of Florence

$\underline{\text { marco.tiberti@gmail.com }}$

This research is part of the $\mathrm{PhD}$ dissertation by M. Tiberti. We would like to thank Donato Romano, Federico Perali, Alberto Zezza, Elisa Ticci, Abdelkrim Araar, John Cockburn and Bernard Decaluwé for their valuable suggestions. The usual disclaimers apply. L. Tiberti is grateful to PEP for financial support. 


\begin{abstract}
:
The main objective of this study is to develop a robust and comprehensive tool to evaluate the effect on households' welfare of different agricultural policies in Tanzania. This is done through a non-separable agricultural household model where production and consumption decisions are considered. In particular, we look at labour market failure, since this is among the major constraints in a context like rural Tanzania. Nonseparability implies that production and consumption decisions are interlinked and that labour allocation is likely to be determined by shadow wages rather than market wages. A two-stage estimation strategy is adopted: the shadow price of family labour is first estimated and then included into the production and demand systems. The impact of a number of agricultural policies on poverty is then estimated. In particular, we evaluate the impact of policies established by the Agricultural Sector Development Programme, as well as changes in food prices.
\end{abstract}

Keywords: Agricultural household models, poverty, agricultural policies, Tanzania

JEL Classification: D12, O12, O13, Q12, Q18 


\section{Introduction and motivation of the study}

The role of agriculture in economic development is a central topic since the early stages of the development thought. Nowadays, it is broadly acknowledged that agriculture changes its role according to the stages of development and that ignoring agricultural growth in early stages of development - i.e. implementing the so-called "jump strategies" - is generally bound to failure.

In addition, agriculture-based growth is generally more effective than non-agricultural-based growth in reducing poverty as shown by Ravallion and Datt (1996), Christiaensen and Demery (2007) and Ligon and Sadoulet (2007). The assumption behind this is that agricultural growth favors lower income deciles proportionally more than higher deciles.

Moreover, many studies showed that farm productivity improvements may also generate positive trickling-down effects on non-farm activities in rural areas (Hazell and Haggblade, 1991; Haggblade et al., 2007). ${ }^{1}$ The policy implication is that agricultural development cannot be dismissed in any poverty alleviation strategy and this is particularly true in countries still dominated by rural economy.

Building on this literature, this research analyzes the potential impacts of agricultural growth in fighting poverty focusing on the increase of household income and agricultural production, with an empirical application to Tanzanian farmers. The choice of Tanzania as case study was made purposely. In fact, Tanzania is still one of the poorest countries in the world and, although Tanzanian economy has grown rapidly since the end of ' 90 s with GDP growing at 6.6 percent per year between 1998 and 2007, household income poverty dropped only slightly both in rural and urban areas, decreasing only by 2.1 percentage points from 35.7 percent in 2000-2001 to 33.6 percent in 2007 (Pauw and Thurlow, 2010).

Tanzania economy is still dominated by agriculture, specifically small-scale farming. Aggregate agricultural output has grown sensibly since the end of '90s. However, as recently discussed by Pauw and Thurlow (2010), agricultural growth was driven by large-scale farmers and growth was very uneven, affecting only a few regions of the country (Pauw and Thurlow, 2010). Therefore, it can be argued that the structure of agricultural growth, favoring large-scale producers of traditional export crops, as well as the poor performance of food crops explain the negligible impact of agricultural growth on poverty and nutrition.

The Tanzanian government has recently recognized the pivotal role of agriculture in reducing poverty. Agricultural sector development is currently at a critical stage as new initiatives have been

\footnotetext{
${ }^{1}$ As argued by Anriquez and Stamoulis (2007, pp.16-17) agricultural growth may help poverty reduction through four main channels: directly, "increasing the income and/or own consumption of small farmers", and indirectly, "reducing food prices, $[\ldots]$ increasing the income generated by the non-farm rural economy" (through the increase in the demand for the goods and services of the rural non-farm sector)", and "raising employment and wages of the unskilled" (being agriculture typically intensive in unskilled labour).
} 
implemented. In particular, the Agricultural Sector Development Programme (ASDP), launched in 2006, is the operational program that carries out the Agricultural Sector Development Strategy (ASDS) as well as broader frameworks such as the National Strategy for Growth and Reduction of Poverty and the Tanzania Development Vision 2025, which endorse the Millennium Development Goals (GoT, 2011).

Hence, Tanzania seems to be a good case study to assess the effectiveness of agricultural policy reform in stimulating agricultural growth and reducing poverty through the analysis of farmers' production and consumption behaviour and the assessment of policy impacts on households' welfare. The main objective of this study is to provide robust fundaments to answer which government intervention aiming at increasing agricultural production is most effective at achieving national poverty objectives. The justification of this research is primarily empirical: it aims at developing a model to measure how changes in agricultural production affect households in terms of poverty, by primarily looking at behavioral changes affecting consumption and production outcomes. Given that the bulk of the poor lives in rural areas and earns most of its income from agriculture $^{2}$, effective agricultural policies are critical for reducing poverty.

From the theoretical viewpoint, this study is an additional contribution to the analysis of farmers' behaviour, and in particular of production and consumption decisions with missing markets, which call for a non-separable agricultural household modelling strategy ${ }^{3}$ (Singh et al., 1986; de Janvry et al., 1991) ${ }^{4}$. Given the features of rural Tanzania (where labour is by far the most important input in farm production and the labour market is very thin), in our analysis we made the hypothesis of labour market failure. Non-separability (due to an imperfect labour market) implies not only that production and consumption decisions are interlinked, but also that labour allocation is likely to be determined by shadow wages rather than market wages. To capture this feature, a twostage estimation strategy was adopted: first the shadow prices of family labour has been estimated and then used to estimate the production and demand systems by means of a multi-input multioutput production system (translog) and a complete demand system (Almost Ideal Demand -AIDSystem). The production and consumption decisions taken under labour market failures are thus interlinked through the family labour (which enters the production system) and its counterpart in the consumption system, which is leisure, both valued at the shadow wage as estimated in the first stage. The models above are able to capture adjustments in production and consumption behaviours resulting from specific policy interventions whose impacts are mimicked through simulations.

\footnotetext{
${ }^{2}$ According to the most recent estimates (GoT, 2011), about 80 percent of the poor live in rural areas and agriculture accounts for 75 percent of rural household incomes.

${ }^{3}$ As known, a separable agricultural household model rests on the assumption that hired labour and family labour are perfect substitutes and that labour market works perfectly.

${ }^{4}$ See Taylor and Adelman (2003) for a brief but exhaustive analytical description of agricultural household models.
} 
Taking inspiration from the agricultural household models approach and the main features of Tanzanian rural economy, this study proposes a partial equilibrium model which estimates the welfare impact of different agricultural policies and price changes. In particular, this is done by modelling farm households' responses in production and consumption decisions in a context with failure in labour market.

With regard to the welfare impact of price changes, most researches take into account the effects of food price change on both consumption and production (Ferreira et al., 2012). However, the behavioural effects in consumption and production decisions are rarely considered accurately (if any). This is the case especially for the production component. Under large price changes (though in the short-to-medium term), neglecting second order effects in consumption and production decisions can bias the final impact on household welfare. Similarly, structural interventions such as those concerning irrigation or mechanisation can produce non-negligible behavioural effects in production decisions. This is why the approach we propose in this study can be particularly appropriate for the kind of phenomena analysed hereafter.

Finally, to the best of our knowledge, there are no studies estimating the substitution effects in consumption and production in the SSA region with cross-section data as effect of agricultural policies and food price changes.

The study is organized as follows. Section 2 explains the estimation strategy and the empirical specification of the agricultural household model, and presents the estimates of the production and demand systems and of the related elasticities. In section 3 a number of micro-simulations of the impact of price changes and of rural policies are first used to predict the change in agricultural profit $^{5}$. This change is then plugged into the demand model, and the new consumption vectors (in real terms) are then generated. Results of these micro-simulations are finally used to draw possible policy implications in terms of poverty reduction. Section 4 summarizes the main findings of the study and the policy implications.

\footnotetext{
${ }^{5}$ Taking into account variations in agricultural profit following price changes, allows to assess properly the impact of price changes for farm households. Indeed, many studies recently assessed the impact of food price crisis by focusing only on consumption behaviour and leaving out production responses. Instead, this study takes into account the farm profit variation (which, for a farm household, is presumably positive in case of an increase in agricultural prices), which partly determines the income effect of the Slutsky equation.
} 


\section{Estimation of Agricultural Household Model}

\subsection{Theoretical model}

In this section we specify a static model to estimate households' production and consumption responses when labour market fails ${ }^{6}$. This is the case of Tanzanian rural economy, which calls for a non-separable agricultural household modelling strategy.

The farm household is assumed to maximize utility subject to technology, budget and market constraints. Drawing, partly, on Henning and Henningsen (2007a), the utility function to be maximized can be represented as follows:

$$
U\left(c_{m}, c_{a}, T-l_{s}^{h}-l_{s}^{m} ; D, R\right)
$$

where $c_{m}$ and $c_{a}$ represent non-agricultural and agricultural consumption goods, respectively; $T$ is total time household available, $l_{s}^{h}$ is on-farm household labour supply, $l_{s}^{m}$ is off-farm household labour supply and $T-l_{s}^{h}-l_{s}^{m}$ is leisure; $D$ represents household characteristics, and $R$ household's resource endowment.

The constraints to the maximization problem are:

$$
\begin{gathered}
q_{a}=q_{a}\left(l_{d}^{h}, l_{d}^{m}, x ; Z\right) \\
p_{m} c_{m}+p_{a} c_{a}=w^{m} l_{s}^{m}+\left(p_{a} q_{a}-w^{m} l_{d}^{m}-w^{h} l_{d}^{h}-p_{x} x\right)+K \\
c_{a} \geq 0 ; c_{m} \geq 0 ; T-l_{s}^{m}-l_{s}^{h} \geq 0 ; l_{s}^{m, h} \geq 0 ; l_{d}^{m, h} \geq 0
\end{gathered}
$$

Equation (2) formalizes the production technology, represented by a multi-input multi-output production function, where $q_{a}$ is a vector of agricultural goods produced by the farm household. Variable intermediate inputs $(x)$, on-farm family $\left(l_{d}^{h}\right)$ and hired $\left(l_{d}^{m}\right)$ labour, and land as quasi-fixed factor $(Z)$ are used in the production process. Equation (3) is the budget constraint where $p_{m}$ is the price of non-agricultural (manufactured) goods; $p_{a}$ is the price of agricultural products; $w^{m}$ is the market wage in the agricultural sector and $w^{h}$ is the shadow wage for agricultural family labour; and $K$ represents all non-wage off-farm incomes.

Equation (4) imposes the usual non-negativity constraints for consumption of food and nonfood goods, leisure, and demand for, and supply of labour.

\footnotetext{
${ }^{6}$ We focused on labour market failures, because this is one of the major constraints in a context like that of rural Tanzania, where labour is the most important input in farm production. Focusing only on labour market failures, we disregarded other important constraints (above all, credit constraints, cf. Feder et al., 1990), as well as other aspects of farmers' decisions like price and production risk (Fafchamps, 1992), which are difficult to catch in a single-period analysis.
} 
If non-separability holds (e.g. due to an imperfect labour market), this implies not only the interaction of production and consumption choices, but also that labour allocation is likely to be endogenously determined by the shadow wage rate rather than the market equilibrium wage rate.

\subsection{Empirical Specification ${ }^{7}$}

Starting from the empirical approach proposed by Henning and Henningsen (2007a and 2007b), we estimated a non-separable agricultural household model using the 2008/2009 Tanzania National Panel Survey Integrated Households Survey (TNPS-1) data. Differently from these and other authors (like Jacoby (1994) and Abdulai and Regmi (2000)), who focused on labour supply, we used estimates of the non-separable model to assess the impact on households' welfare of different agricultural policies and price changes.

A two-stage estimation strategy is adopted, estimating first the shadow prices of family labour through production function modelling. After the shadow wage rate is included into a multi-input multi-output production system (translog) and a complete demand system (AID System), production and consumption functions are then estimated. The production and consumption decisions made when labour market fails are thus interlinked by family labour (which enters the production system) and its counterpart in the consumption system, i.e. leisure, setting both prices at the shadow wage level as estimated in the first stage.

A similar approach makes possible an assessment of the adjustments in production (both in output and input) and consumption patterns as a result of changes in specific decision variables.

The shadow wage of household labour was estimated by following the procedure proposed in Jacoby (1993). The Cobb-Douglas functional form was used, despite its limitations, because of its easiness of estimation and interpretation.

To assess the level and interactions among different farm products resulting from the implementation of alternative agricultural and price policies, we estimated output supply and input demand elasticities. This was done by estimating a system of equations derived from a restricted profit-maximization specification. The production technology is represented by a translog multiinput multi-output profit function, following the methodology proposed, among others, by Fulginiti and Perrin (1990).

On the consumption side, an AID System proposed by Deaton and Muellbauer (1980) was used to estimate the impact of changes in prices and income on households' consumption behaviour.

\footnotetext{
${ }^{7}$ A detailed description of empirical specification and estimation strategy is reported in Annex 1.
} 


\subsection{Households’ Production and Consumption Behaviour: Estimation Results ${ }^{8}$}

\subsubsection{Shadow wage estimation}

The OLS and IV estimates of the Cobb-Douglas production function are reported in table 1. The OLS regression displays a high determination coefficient $\left(\mathrm{R}^{2}=0.3812\right)$ and most of the OLS estimated coefficients have the expected signs. Most inputs have significantly positive effects on agricultural output. All labour typologies have impacts significantly different from zero. Moreover, while the impact of hired female labour is greater than that of male hired labour, for family labour the impact is reversed ${ }^{9}$. This is probably because of activities such as ploughing, which are undertaken by men, contribute marginally more to output than activities such as weeding and transplanting in which females are largely engaged in Tanzania. Land quality, irrigation and mechanization have a significantly positive effect on farm production. The household head's schooling has not a significant impact on agricultural output, not supporting the widely accepted role of human capital in improving farmers' production. Also household head's age is not significant. Infrastructures such as roads and markets have not statistically significant effects on production.

However, the physical inputs are likely to be endogenous. Therefore, instrumental variables (IV) are included to estimate the production function ${ }^{10}$. Durbin and Wu-Hausman tests are carried out to check for endogeneity. Both tests suggest that the OLS model is rejected, which indicates the need for an IV procedure. Moreover, the Sargan test, checking for the validity of instrumental variables (i.e. uncorrelated with the error term), confirms that instruments are valid. Coefficients from the IV estimate are used to estimate the household shadow wage.

Table 2 reports the estimates of the household shadow wages obtained using equation (A.2). The chi2-statistics shows that the null hypothesis of equality between the marginal product and market wage rates can be rejected for both the men and women sample. ${ }^{11}$ The samples finally retained to estimate (A.2) include men and women employed as household labourers and off-farm wage workers. Following Jakoby (1993), the wage rate was instrumented using the worker's age and level of education, as well as the quadratic terms of these variables. This finding supports the

\footnotetext{
${ }^{8}$ In Annex 3 there are definitions, means and standard deviations of all variables used in main empirical specifications.

${ }^{9}$ This result is consistent with the findings of Abdulai and Regmi (2000), but contrasts earlier findings by Skoufias (1994) who found that in India family female labour showed a greater impact on output than family male labour.

${ }^{10}$ Set of instruments used in the production function analysis:

- Household composition variables: number of children (aged $<15$ ), number of elderly (aged $>60$ ), number of female adults (aged $>14$ and $<61$ ), number of male adults (aged $>14$ and $<61$ );

- District level prices and wages: price of maize (logarithm), adult farm daily wage;

- Dwelling characteristics: home ownership dummy ( 1 if own, 0 otherwise), cooking fuel dummy ( 1 if electricity or gas, 0 otherwise), source of drinking water dummy ( 1 if piped water inside or outside dwelling, 0 otherwise).

${ }^{11}$ This finding supports earlier results by Jacoby (1993), Skoufias (1994) and Abdulai and Regmi (2000).
} 
hypothesis of interdependence of production and consumption decisions by agricultural households and justifies the use of a non-separable model.

Table 1: Production function estimates ${ }^{(i)}$

\begin{tabular}{|c|c|c|}
\hline $\begin{array}{c}\text { Dependent variable: loutput_value } \\
\text { Independent variables }\end{array}$ & $\begin{array}{l}\text { OLS } \\
\text { Coef. }\end{array}$ & $\begin{array}{c}\text { IV } \\
\text { Coef. }\end{array}$ \\
\hline lhh pesticides ${ }^{\mathrm{a}}$ & $0.072 *$ & -0.608 \\
\hline lhh_inorganic_fert ${ }^{\mathrm{a}}$ & $0.171 * * *$ & 0.198 \\
\hline lhh_organic_fert ${ }^{\mathrm{a}}$ & $0.019^{*}$ & $0.272 * *$ \\
\hline lhired_female ${ }^{a}$ & $0.152 * * *$ & 0.158 \\
\hline lhired_male ${ }^{\mathrm{a}}$ & $0.066^{* * *}$ & 0.090 \\
\hline lhh_land & $0.501 * * *$ & $0.548 * * *$ \\
\hline lhh_tot_lab_f & $0.054 * * *$ & $0.102 * *$ \\
\hline lhh_tot_lab_m & $0.102 * * *$ & $0.108 * * *$ \\
\hline hh_head_age & -0.008 & -0.013 \\
\hline hhhead_age ${ }^{2}$ & -0.093 & 0.000 \\
\hline hh_head_sex & $-0.000^{*}$ & -0.118 \\
\hline literate & 0.005 & 0.121 \\
\hline land_quality & $0.330 * * *$ & $0.353 * * *$ \\
\hline irrigation & $0.362 * *$ & 0.681 \\
\hline lroad & -0.019 & 0.023 \\
\hline lmarket & 0.016 & -0.038 \\
\hline lmechanization & $0.088 * * *$ & $0.047^{*}$ \\
\hline cons & $8.524 * * *$ & $8.959 * * *$ \\
\hline $\begin{array}{ll}\mathbf{R}^{2} & 38.12\end{array}$ & & \\
\hline \multicolumn{3}{|l|}{ IV test results } \\
\hline Wu-Hausman: $F(5,1837)=3.602$ & & $\mathrm{p}=0.0030$ \\
\hline Sargan test: chi-sq(3) $=9.113$ & & $\mathrm{p}=0.0278$ \\
\hline
\end{tabular}

Table 2: Test of the equality between market and shadow wages $^{(i), \text { a }}$

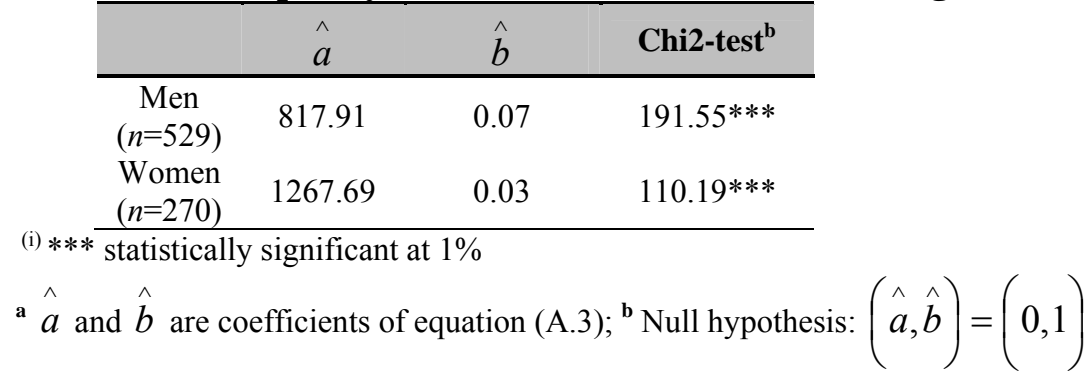

Source: Authors' estimations using TNPS-1

\subsubsection{Production ${ }^{12}$}

Coefficients of the output shares, estimated through a translog production system (cf. equation (A.6)), as well as the profit function (equation (A.4)) are reported in Table 3. Profit share functions refer to (1) cereals, (2) fertilizers and pesticides, (3) household labour and (4) hired labour, while

\footnotetext{
${ }^{12}$ Although we are aware of the presence of different farming systems in Tanzania, this analysis was conducted ignoring such differences, since a detailed analysis of different farming systems is beyond the scope of this study.
} 
the other crops share (5) is estimated by difference (all these shares sum to one). Furthermore, two fixed inputs $(Z)$ are included in the system: $Z_{l}$ is the area-weighted average number of irrigations; $Z_{2}$ is the land input measured as hectares cultivated by farms in the long rainy season 2008/2009. Finally, the profit function includes also other variables ${ }^{13}-$ such as the use of improved seeds, the ownership of an ox-plough, the household head's education status (literate or not) and the access to extension services - to capture the effect of these other factors on production. ${ }^{14}$

All own-price coefficients have the expected sign, except the one of household labour, but only those related to fertilizers and pesticides and hired labour are significantly different from zero. This means that the output supply and factor demand equations are consistent with underlying profit maximization theory.

Land is highly statistically significant in the profit function, while irrigation shows a complementary effect with other inputs (fertilizers and pesticides), but it is not significant in the profit function ${ }^{15}$. All dummy variables (i.e. improved seeds, ox-plough, household head educational attainment and extension services) have the expected signs and are highly significant (except extension services, whose coefficient is not significant).

\footnotetext{
${ }^{13}$ These variables were included as dummies because of data limitations. As a result, they appear in the profit function only, since they were not interacted with prices (see, for example, Olson and Zoubi, 2001).

${ }^{14}$ Infrastructur variables, like distance to road or the presence of a market in the village, were not statistically significant in any specification. Therefore, they were dropped.

${ }^{15}$ The null impact of irrigation may be explained by the fact that irrigation is likely to be ineffective in reducing the effects of severe drought like that occurred in Tanzania in 2008/2009. This is due by the fact that irrigation in Tanzania is prevalently gravitational irrigation and, hence, in case of severe droughts, the rivers dry up. This leads to insufficient water for irrigation (a similar result can be found in Christiaensen et al., 2005).
} 
Table 3: Restricted parameters estimates of the translog profit function ${ }^{(i)}$

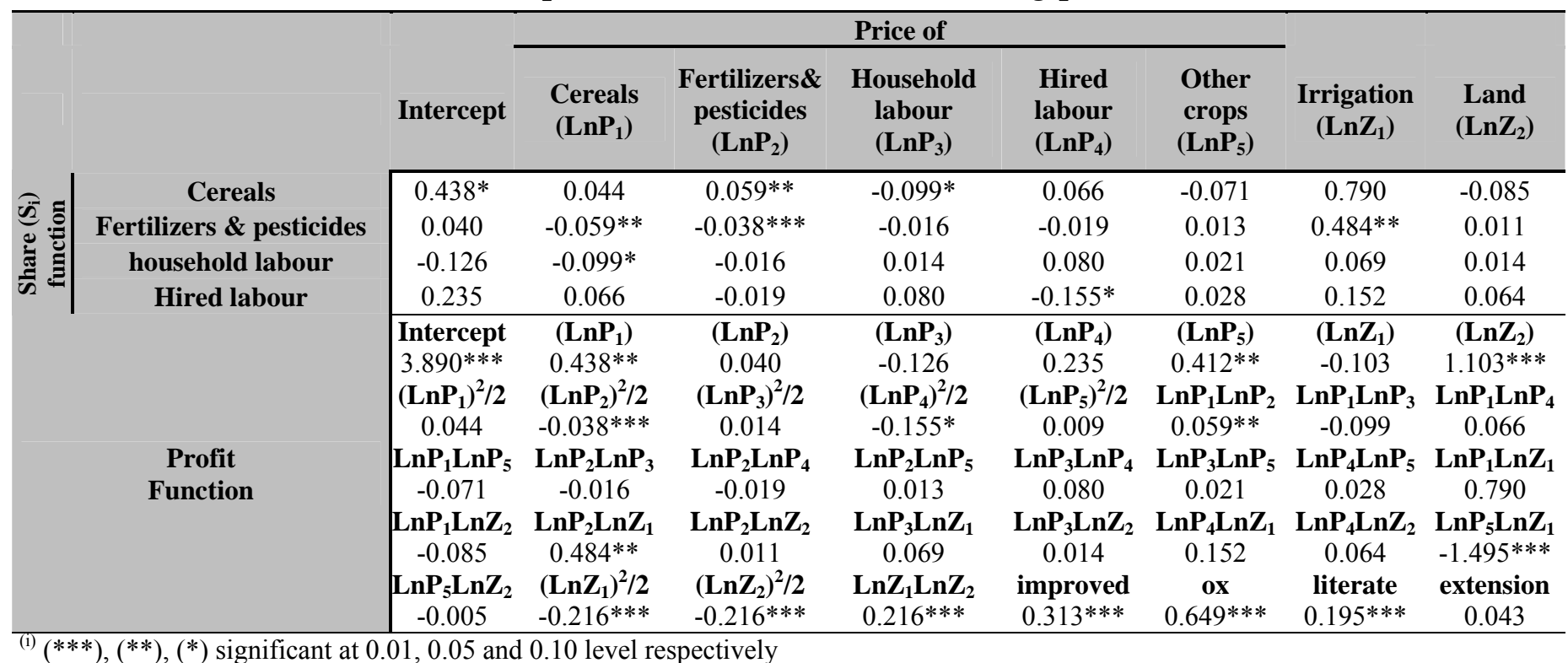

Source: Authors' estimations using TNPS-1 
The parameters that are shown in table 3 are used to estimate the price elasticity of the quantity of output and input. Elasticities can be easily used to assess the impact of a price change on the agricultural output.

The full set of price elasticities for output supply and input demand were computed using sample means, according to equations (A.7) and (A.8) (Table 4). Both supply of cereals and other crops are inelastic (below 1). This result is clearly affected by the relevance in the profit share of maize and other crops (such as tubers) which are mainly grown for self-consumption purposes. This is also indication of the poor diversification in food consumption preferences for farmers. In other words, the increase in a crop's price does not induce the farmer to produce more of that item to sell it in the market and by substituting its consumption with something else. Availability of other food products is indeed limited, especially in the rural context.

Supply cross-price elasticities are positive, revealing a complementary relationship among the commodities, a result in line with the findings in Ball (1988), Fulginiti and Perrin (1990) and Colby et al. (2000). This implies that the increase in the commodity price leads new inputs to be drawn into general production, leading, in turn, to an increase in the production of other products. Moreover, this suggests a low potential for diversification in Tanzanian agriculture.

The result that supply cross-price elasticities are larger than own-price elasticities suggests that production is likely to be driven by consumption decisions. When one crop's price increases farmers are diverted to consume less of that crop. They are likely to be induced to produce substantially more of the other crop in order to compensate for the lower consumption of the first product. This mechanism may be particularly true for farmers engaged in only one crop (or category of crops) production. At this regard and based on the sample used for these estimates, we found that slightly less than half percent of farmer households produce either cereals or other crops.

All cross-price elasticities for inputs are negative, which means that inputs are complements: an increase in one input price, holding other categories' prices constant, decreases other inputs demand. Similar results are reported in Fulginiti and Perrin (1990). The negative cross-price elasticity of inputs demand to household shadow wage, market wage and fertilizer price shows that the combined use of household and market labour and other inputs increases agricultural production synergistically. Indeed, the decrease of any of these three variable inputs induces a lower demand of the other inputs. Also, the size of input elasticities with respect to output prices reveals that the input demand is more responsive to the price of cereals than to that of other crops. Moreover, if we compare the cross-price elasticities of fertilizers/pesticides $(F P)$ and household labour $(H L)$ (e.g. $\left.\left|\varepsilon_{F P, H L}\right|>\left|\varepsilon_{H L, F P}\right|\right)$, we confirm the labour intensive feature of the agricultural production system in Tanzania. Cross-price elasticities of output supply to input prices are always negative: this is 
consistent with the economic theory. Finally, consistently with the fact that household labour accounts for about $70 \%$ of total input costs, its own-price elasticity results to be larger than for other inputs and hired labour.

\section{Table 4: Output and input price elasticity matrix ${ }^{(i)}$}

\begin{tabular}{c|c|ccccc}
\hline \multicolumn{2}{c}{} & \multicolumn{5}{c}{ Price of } \\
\cline { 3 - 7 } & & Cereals & Other crops & Other inputs & Household labour & Hired labour \\
\cline { 3 - 7 } & Cereals & $0.811 * * *$ & $1.453 * * *$ & $-0.744 * * *$ & $-1.283 * * *$ & $-0.238 * * *$ \\
& Other crops & $1.739 * * *$ & $0.499 *$ & $-0.768 * *$ & $-1.213 * * *$ & $-0.257 * * *$ \\
& Other inputs & $1.711 * * *$ & $1.476 * * *$ & $-1.728 * * *$ & $-1.207 * * *$ & $-0.251 * * *$ \\
& Household labour & $1.867 * * *$ & $1.476 * * *$ & $-0.764 * *$ & $-2.239 * * *$ & $-0.341 * * *$ \\
& Hired labour & $1.546 * * *$ & $1.392 * * *$ & $-0.709 * * *$ & $-1.518 * * *$ & $-0.712 * * *$ \\
\hline
\end{tabular}

(i) Elasticities are estimated at the weighted average of output and input shares. Z-stat for elasticities are calculated by bootstrapping with replacement (after 1,000 replications). Note that $(* * *),(* *),(*)$ identify elasticities which are statistically different from 0 at $0.01,0.05$ and 0.10 level respectively

Source: Authors' estimations using TNPS-1

\subsubsection{Consumption}

Table 5 shows that most of the estimated parameters of the AID system are highly significant. Among demographic variables, household size negatively influences the expenditure share of most food groups, while the number of children has a positive and significant impact only on the consumption share of fish, oil and fats and meat, eggs and dairy and a negative and significant effect on the consumption share of pulses and dry and leisure.

The sign of own price and income (expenditure) elasticities, reported in Table 6, are consistent with theory and their magnitudes are within the expected ranges. Other cereals, fish, meat, eggs and diary, and non-food consumption are very sensitive to own price changes, while starches - mostly consumed by the poor - are quite unresponsive to their own price.

Except for starches, income elasticities are positive for all commodity groups. Meat, eggs and diary, other cereals, sugar and sweets, oil and fats, beverages, fish and non-food have expenditure elasticities above one, indicating that these commodities are superior goods and that the diet among the poor is limited to quite a few food items. On the contrary, as income increases consumers tend to spend proportionately less on maize and pulses, vegetables and fruit, and salt and spices. Finally, income elasticity associated to leisure is lower than one; this result may indicate that, as income increases, people allocate more time on work activities and reduce their time for leisure. This is true particularly in rural areas. 
Table 5: AID System estimates ${ }^{(i)}$ (ii)

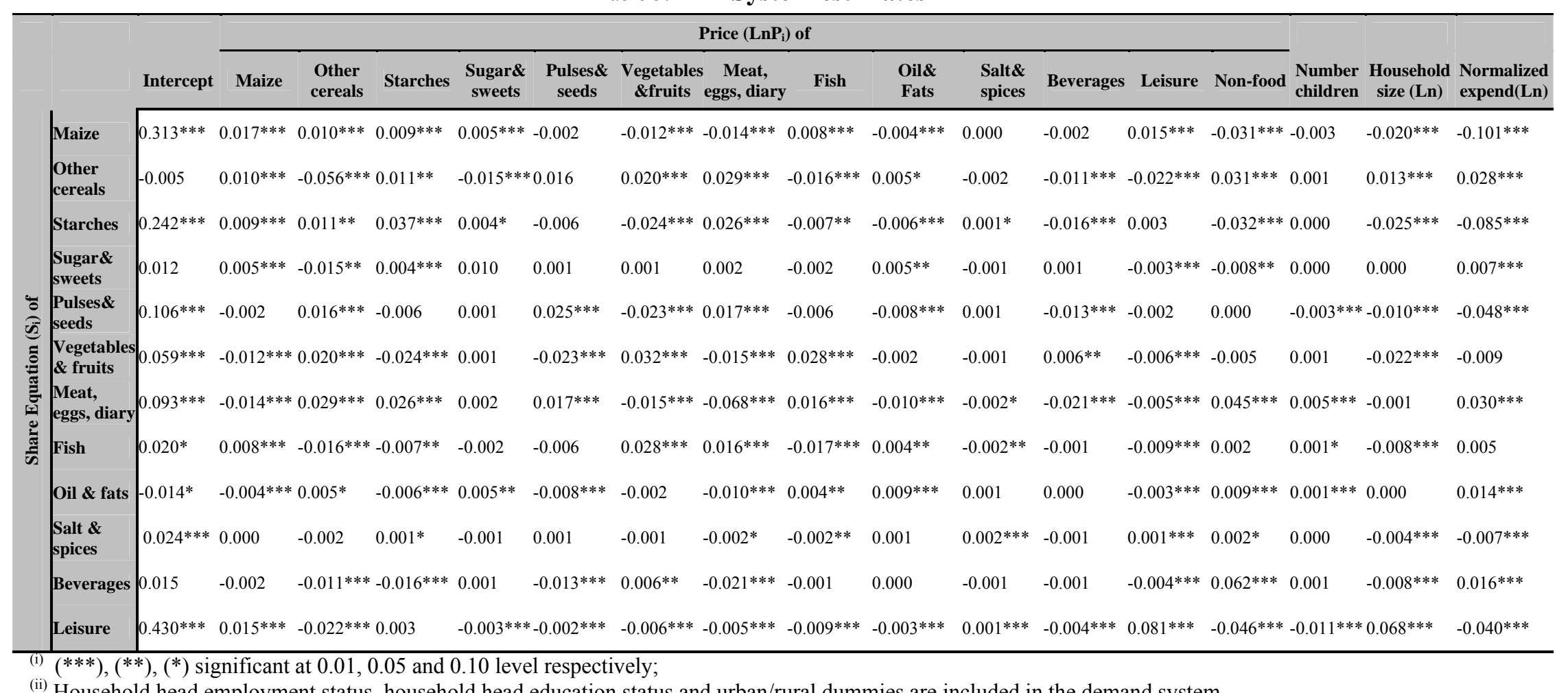

(ii) Household head employment status, household head education status and urban/rural dummies are included in the demand system

Source: Authors' estimations using TNPS-1 
Table 6: Expenditure price and expenditure elasticity matrix ${ }^{(i)}$

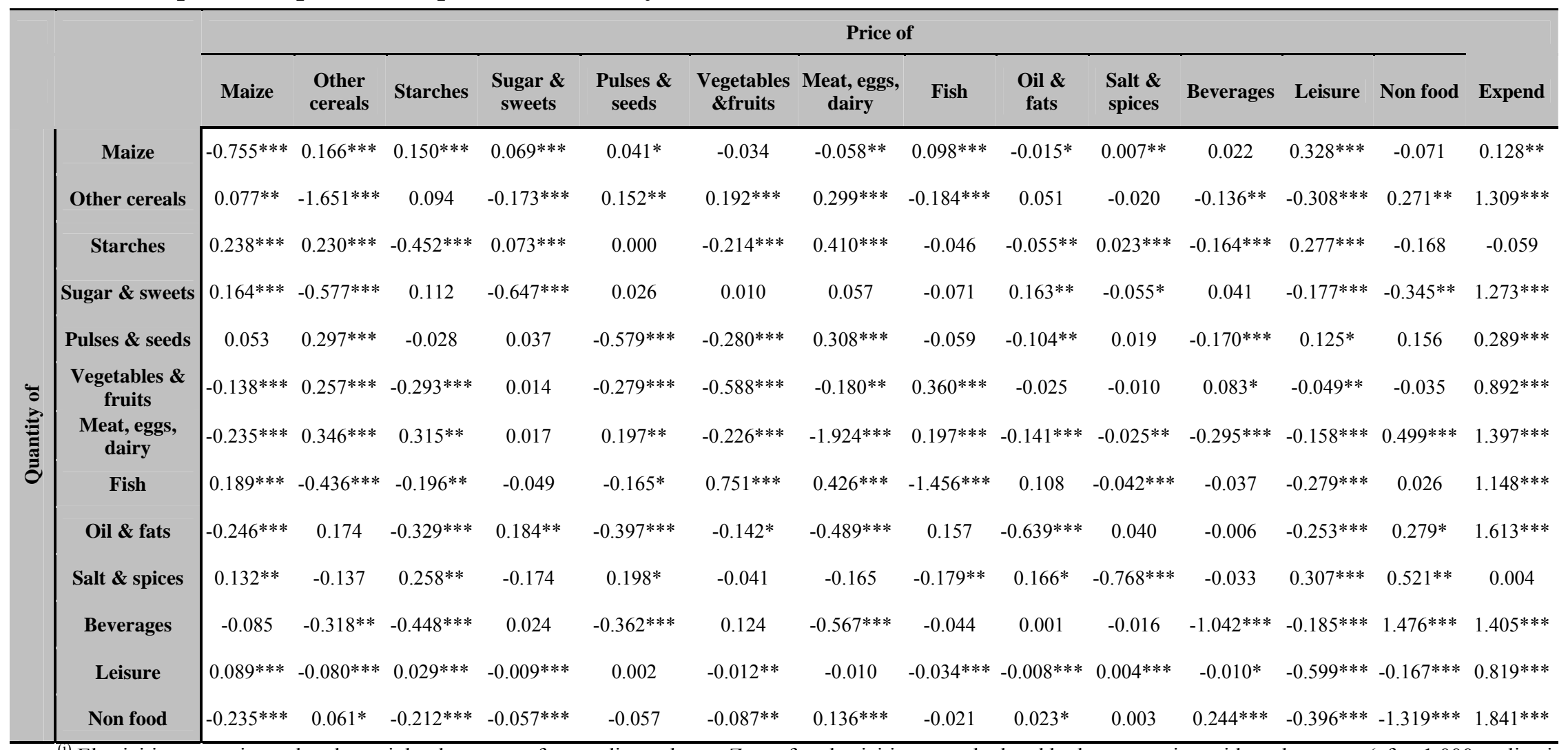

${ }^{(i)}$ Elasticities are estimated at the weighted average of expenditure shares. Z-stat for elasticities are calculated by bootstrapping with replacement (after 1,000 replications). Note that $(* * *),(* *),(*)$ identify elasticities which are statistically different from 0 at $0.01,0.05$ and 0.10 level respectively

Source: Authors' estimations using TNPS-1 


\section{Simulation of Agricultural Policies and Price Changes}

\subsection{Description of agricultural policies and prices variation simulations}

The estimated model was used to assess the impacts on households' welfare of the full implementation of phase 1 of the Agricultural Sector Development Program (ASDP) (launched in 2006/2007 and expected to be concluded in 2012/2013) and the change in output prices. These scenarios are likely to have been affecting Tanzanian households, particularly in rural areas. Given the top-rank priority of the former in Tanzanian Government's objectives, the simulations will focus primarily on the policy reform, applying it to the status quo (baseline) without considering other changes that took place since the model's reference year, i.e. 2008-2009. However, there are changes that cannot be ignored due to their non trivial impacts on households' welfare. We simulated in fact the price fluctuations that took place since the beginning of the food crisis up to the date of the analysis (November 2011), alone and their combined effect with of policy reform.

The ASDP is part of the Agricultural Sector Development Strategy (ASDS) and the broader National and Global Policies, including the National Strategy for Growth and Reduction of Poverty (most commonly known as MKUKUTA), the Tanzania Development Vision 2025, and the Millennium Development Goals.

Priority actions within the ASDP are increasing the use of modern inputs and technologies (i.e. irrigation, improved seeds, erosion control, chemical fertilizers, ox-ploughs), improving support services (including agricultural research and extension services), and providing better agricultural marketing infrastructures as well as formal and informal credit institutions.

In this section we will assess the impacts on poverty of a number of policies included in the Agricultural Sector Development Programme, namely ${ }^{16}$ (Table 7):, increasing the proportion of farm households using improved seeds from 17.9 percent to 35 percent (Simulation 1), increasing the proportion of farm households using mechanization (ox-plough) from 7.5 percent to 30 percent (Simulation 2), increasing the percentage of farmers having access to crop extension services from

\section{6 percent to 55 percent (Simulation 3).}

The whole package of ASDP measures described above has been also simultaneously simulated in Simulation 4: this allows the assessment of how effective the agricultural policies designed by Tanzanian Government are and to compare their achievements with the outcome targets set by the Agricultural Sector Development Programme (i.e. leading to a $24 \%$ headcount ratio in rural areas).

\footnotetext{
${ }^{16}$ Other instruments included in the ASDP were not simulated since in the profit model the variables related to these measures were not statistically significant (e.g., variables regarding SACCOs and rural credit, or variables regarding infrastructure as the distance to a market and to a principal road).
} 
To assess the different impacts of these policies on poverty, four different targeting profiles were hypothesized ${ }^{17}$. They can be grouped in two categories. The first category adopts income criteria and compares a targeting oriented to the poorest groups of population ${ }^{18}$ ("pro-poor"), versus a policy implementation oriented to those who have the highest probability ${ }^{19}$ of being directly interested by the policies ("no targeting"). Of course, under this "pro-poor" scenario we made the hypothesis that the policy-maker perfectly knows the income distribution of Tanzanian population. This is unrealistic, but it wants to represent uniquely the top-performing reference if effective proxy-means test schemes are implemented. The second group identifies two targeting profiles according to land size: one oriented to "smallholders" and one oriented to farmers owning relatively more land ("non-smallholders") $20,21$.

Another set of simulations refers to changes in the price of outputs. The impact of the increase in cereals prices occurred over the last years is assessed in Simulation $5^{22}$, entering both the consumption (negative effect) and production (positive effect). According to existing data ${ }^{23}$, in November 2007 Tanzania showed the lowest cereals prices over the second half of 2000s; in September 2009 (which is also the last month of our dataset), instead, cereals prices peaked at their highest value (already reached in February 2008). Therefore we considered the price changes ${ }^{24}$ that took place between May 2007 and September 2009; specifically, we simulated a (weighted) price increase of cereals by around $132.6 \%$ in the aforementioned period. Simulation 6 takes into account the price change for cereals since October 2009 (the month following the end of our questionnaire)

\footnotetext{
${ }^{17}$ A limitation in our approach is that we consider only policy impacts, while there are important issues related for instance to the implementation costs that we do not take into account. For example a pro-poor targeting will probably be more expensive than a random policy implementation.

${ }^{18}$ According to this approach, the simulated policies progressively include households from the poorest quintiles with higher agricultural profit/income ratio up to the ranking position where the policy-specific target has been achieved. By following this approach, not necessarily easy to be put in place, we wanted to target the poorest households whose income mostly comes from the agricultural sector.

${ }^{19}$ For this purpose we estimated probit and tobit models with the variables to be simulated (i.e. improved seeds, oxplough, extension services) as dependent variables. In this case, households were selected according to the probability predicted by these binomial models, starting from households not endowed with those inputs but showing the highest probability of having them, up to the ranking position where the policy-specific target is achieved.

${ }^{20}$ It would be misleading to define these farmers as "large farmers". Indeed, those are farmers who cultivate on average less than 5 ha of land.

${ }^{21}$ For "smallholders" and "non-smallholders" targeting profiles, we identified the groups of households with land size lower and greater than 2 ha respectively. Within these groups, we selected those which have not these inputs (improved seeds, ox-plough and extension services) and choose randomly the policy beneficiaries up to the policy-specific target is achieved.

${ }^{22}$ For the production system we took into account variations in the price of maize and rice as proxy of the price of the "cereals" category, while for the demand system we used the change in the price of maize for the "maize" category and the price of rice as proxy of the price for the "other cereals" category. Given the lack of regional data, we used price changes referring to Dar es Salaam. We are aware that this may overestimate the effect of price increase. Moreover, we made the hypothesis that changes in consumption and production prices are equal, which may be quite a strong assumption, especially under large and rapid price increases.

${ }^{23}$ Cereals prices data are from FAO/Global Information and Early Warning System on Food and Agriculture (GIEWS) online dataset (FAO, 2011).

${ }^{24}$ Cereals prices were reported back at their value in May 2007.
} 
to November 2011 (the last month for which data were available), which corresponds to a (weighted) decrease by around $25 \%$.

Finally, Simulation 7 combines the complete ASDP package of measures simulated (Simulation 4) with the price trend considered in Simulation 6. This allows the assessment of the "true" impact of the ASDP policies on poverty.

Since the increase in prices affects all population quintiles, simulations of price changes (Simulations 5 and 6) were carried out without any targeting (e.g., pro-poor versus non pro-poor, or smallholders versus non-smallholders).

\subsection{Poverty estimates ${ }^{25}$}

Before going into the details of poverty results, we should remind that the ASDP policies are nowadays still far from their full implementation. The results shown below thus represent the potential effectiveness of the ASDP policies under their full implementation. As the information on the costs associated to each of the policies proposed hereafter are not readily available, the analysis (for the moment) does not take into account the effectiveness per shilling spent and the results are then not normalized by the cost of the policy.

These simulations show that, considering single agricultural policies within the ASDP package, mechanization (Sim2, i.e. ox-plough adoption) is the most effective policy for increasing farm profits and, as a result, reducing poverty (both headcount ratio and poverty gap). This is true particularly under the "pro-poor" targeting scheme (rural HCR deceases by 2.6 percentage points).

The adoption of improved seeds significantly reduces rural poverty by around 1.1 percentage points under both income targeting approaches (while poverty gap reduction is larger in case of a "pro-poor" targeting), and by 1 percentage point under "non-smallholders" targeting, while it has not any statistically significant impact when the smallholders are targeted.

In case of pro-poor targeting, the implementation of the whole ASDP package has a strong impact on headcount ratio and poverty gap reduction (in rural areas nearly 4.7 and 2.1 percentage points respectively). The results are far more impressive if the policies are carried out in a more realistic scenario that takes into account the actual changes in food prices since the time the survey was carried up to November 2011 (Sim 7). Here, the implementation of the whole ASDP package reduces rural HCR by 8.6 percentage points in rural areas. Poverty gap decreases by 3.1 percentage points. Anyway, even with a pro-poor targeting, the simulated results are lower than the expectations of the Tanzanian government about the impact of ASDP in reducing poverty.

\footnotetext{
${ }^{25}$ Poverty estimates, as well as significance tests and dominance curves were carried out by using the DASP program (Araar and Duclos, 2009).
} 
Without targeting, ASDP is, obviously, less effective in reducing headcount ratio (3.1 percentage points in rural areas and a null impact in urban areas), but it has, however, a strong impact in reducing poverty. This suggests that, in a context like Tanzania, regardless of targeting, agriculture can be a key in reducing poverty. In addition, a "pro-poor" targeting implies a trade-off: a more effective poverty reduction implies a higher implementation cost due to targeting.

If isolated, the price changes that took place between October 2009 and November 2011 (Sim 7) led to a reduction by 3.4 percentage points in the headcount ratio ( 4 percentage points in rural areas) and a decrease by 1 percentage point in poverty gap.

Finally, the increase in food prices had a huge impact on households' welfare. The impact on poverty of an increase in cereals prices as the one occurred since the onset of the food price crisis in 2007 (Sim 5) is impressive. Indeed, ceteris paribus food prices increase led HCR from 26 to 32.9 percent. In addition, the food price jump increased poverty gap from 7.3 (simulated poverty gap in May 2007) percent to 9.4 percent (poverty gap at base run). For farm households the increase in food prices had minor effect on poverty. However, in general, the increase of farm profit following the hike in food prices did not succeed in neutralising the negative effect on real consumption.

This has an immediate policy implication: that is the government should intervene to reduce price movements to prevent adverse effects in terms of poverty and income distribution.

Surprisingly, a targeting oriented to those who have relatively more land results in a more effective headcount ratio reduction as well as poverty gap reduction. Seemingly, this result is in contrast with the widely accepted statement that focusing on smallholders, instead of large farmers, leads to better results in terms of poverty reduction. Actually, "non-smallholders" targeting does not refer to large farmers, which are not significantly represented in the sample, but to farmers owning relatively more land than "smallholders", but with an absolute low endowment of land ("nonsmallholders" have, on average, less than 5 ha of land). In addition, this is related to the crucial role played by land in farming: land is indeed the limiting factor for smallholders, whose very low land endowment ${ }^{26}$ prevents the possibility of increasing agricultural production and profit. Apparently, those endowed with fewer land have greater difficulties in getting out poverty as they live further from the poverty line, while targeting policies to those who have relatively more land leads to better results in terms of poverty reduction. ASDP policies are less effective in increasing farm profits of those owing fewer lands: the estimation of the production system showed the importance of land as a major input in farm production (cf. section 2.3.2) and perhaps this is a limiting factor in ASDP implementation. All this clearly appears in Figure 1 where profit variation due to the implementation of the full ASDP package under the "smallholders" targeting scheme is

\footnotetext{
${ }^{26}$ Smallholders have, on average, 1.24 ha of land.
} 
substantially lower than the one simulated under the "non-smallholders" program. This is verified along the whole distribution of household welfare, including below the poverty line. Given the structural constraints faced by farmers with smaller land size, the ASDP package results to be significantly less effective on agricultural production when smallholders are targeted and, consequently, changes in poverty gap as well as HCR are lower than under the "non-smallholders" targeting approach.

Indeed, it is well-known that access to land is a crucial issue in many Sub-Saharan African countries $^{27}$ and particularly in Tanzania, a country abundant in arable land but with a very sticky land market. This calls for a renewed effort in land reform ${ }^{28}$.

To sum up, this has two main policy implications: (i) there is a need for a new land reform facilitating the access to land for smallholders ${ }^{29}$, and (ii) in absence of a land reform, if the policy objectives are the reduction in the overall poverty, it is better to target relatively larger farmers.

As shown in Figure 2, under the "non-smallholder" simulation, the ranking of the poverty impact associated to the different scenarios is found to be robust according to a fairly large range of poverty lines as well as to poverty indices of class 1 and 2. More specifically, we can conclude that consumption distribution under 2007 cereal prices (Sim5) always dominates all distributions simulated under the "non-smallholders" targeting.

On the contrary, under the "pro-poor" targeting results are less robust. Consumption distribution derived with 2007 cereal prices dominates all distributions except - for poverty lines lower than the official threshold - the one under 2011 cereal prices together with the ASDP package (Sim7). The poverty curve associated to the ASDP package (Sim4) is found to dominate the one estimated with 2011 cereal prices (Sim6) until around the official poverty line; after that threshold the two curves cross and the dominance result is then reversed. Finally, with regard to poverty gap, under the "pro-poor" targeting the distribution under 2011 cereal prices together with the ASDP package (Sim7) dominates the one under 2007 cereal prices (Sim5) for poverty lines lower than around 1.3 times the official threshold. In addition, the ASDP package (Sim4) produces robustly better results in terms of poverty reduction than the 2007 cereal prices scenario (Sim5) for poverty lines lower than around $70 \%$ of the official line.

\footnotetext{
${ }^{27}$ The problem of access to land in Africa has recently become again a hot topic in the development agenda (see, for example, de Janvry and Sadoulet, 2005; Deininger, 2009).

${ }^{28}$ The Tanzanian government has recently reckoned the problem and the Tanzanian Ministry of Lands, Housing and Human Settlement Development is now involved in a significant number of projects to implement Tanzania's land law reform, which has been enforced since May 2001. However, its implementation is slow and geographically uneven, and not much is known about how the reform affected the distribution of land.

${ }^{29}$ It is evident that a land reform in the context of Tanzanian agriculture may represent a win-win option, which improves equality as well as efficiency.
} 
Table 7: Poverty estimations ${ }^{(i)}$

\begin{tabular}{|c|c|c|c|c|c|c|c|c|c|c|c|c|}
\hline \multirow{3}{*}{ Simulation $^{(i i)}$} & \multicolumn{6}{|c|}{ Headcount ratio $(\%)$} & \multicolumn{6}{|c|}{ Poverty gap (\%) } \\
\hline & \multicolumn{3}{|c|}{ Pro-poor } & \multicolumn{3}{|c|}{ No targeting } & \multicolumn{3}{|c|}{ Pro-poor } & \multicolumn{3}{|c|}{ No targeting } \\
\hline & Urban & Rural & All & Urban & Rural & All & Urban & Rural & All & Urban & Rural & All \\
\hline Base year & 17.64 & 37.64 & 32.89 & 17.64 & 37.64 & 32.89 & 4.68 & 10.86 & 9.39 & 4.68 & 10.86 & 9.39 \\
\hline Sim 1 & 17.64 & $36.52 *$ & $32.03 *$ & 17.64 & $36.52 *$ & $32.03 *$ & 4.58 & $10.25^{*}$ & $8.90^{*}$ & 4.68 & $10.68 *$ & $9.25 *$ \\
\hline $\operatorname{Sim} 2$ & 17.59 & $35.00 *$ & $30.86^{*}$ & 17.64 & $35.66^{*}$ & $31.38^{*}$ & 4.39 & $9.49 *$ & $8.28^{*}$ & 4.60 & $10.13 *$ & $8.82 *$ \\
\hline Sim 3 & 17.47 & 37.49 & $32.74 *$ & 17.64 & 37.53 & 32.81 & 4.66 & $10.75^{*}$ & $9.30^{*}$ & 4.68 & 10.82 & 9.36 \\
\hline $\operatorname{Sim} 4$ & 17.20 & $32.91 *$ & $29.18^{*}$ & 17.64 & $34.59 *$ & $30.57 *$ & 4.19 & $8.73^{*}$ & $7.65^{*}$ & 4.60 & $9.93 *$ & $8.66^{*}$ \\
\hline $\operatorname{Sim} 5$ & $12.13^{*}$ & $30.34 *$ & $26.01 *$ & $12.13 *$ & $30.34 *$ & $26.01 *$ & $3.56^{*}$ & $8.46^{*}$ & $7.30^{*}$ & $3.56^{*}$ & $8.46^{*}$ & $7.30^{*}$ \\
\hline Sim 6 & $16.21 *$ & $33.60^{*}$ & $29.47 *$ & $16.21 *$ & $33.60 *$ & $29.47 *$ & $4.20 *$ & $9.60 *$ & $8.32 *$ & $4.20 *$ & $9.60 *$ & $8.32 *$ \\
\hline $\operatorname{Sim} 7$ & $15.78^{*}$ & $29.00 *$ & $25.86^{*}$ & $16.05^{*}$ & $31.12 *$ & $27.54 *$ & $3.78^{*}$ & $7.72 *$ & $6.78^{*}$ & $4.13 *$ & $8.79 *$ & $7.68 *$ \\
\hline \multirow[t]{2}{*}{ Simulation } & \multicolumn{3}{|c|}{ Smallholders } & \multicolumn{3}{|c|}{ Non-Smallholders } & \multicolumn{3}{|c|}{ Smallholders } & \multicolumn{3}{|c|}{ Non-Smallholders } \\
\hline & Urban & Rural & All & Urban & Rural & All & Urban & Rural & All & Urban & Rural & All \\
\hline Base year & 17.64 & 37.64 & 32.89 & 17.64 & 37.64 & 32.89 & 4.68 & 10.86 & 9.39 & 4.68 & 10.86 & 9.39 \\
\hline Sim 1 & 17.50 & 37.64 & 32.86 & 17.64 & $36.64 *$ & $32.13 *$ & 4.66 & 10.78 & 9.32 & 4.65 & $10.56^{*}$ & $9.16^{*}$ \\
\hline $\operatorname{Sim} 2$ & 17.50 & $37.24 *$ & $32.55^{*}$ & 17.56 & $35.98 *$ & $31.60 *$ & 4.62 & $10.59 *$ & $9.18^{*}$ & 4.62 & $10.31 *$ & $8.96^{*}$ \\
\hline Sim 3 & 17.58 & 37.64 & 32.88 & 17.64 & 37.49 & 32.78 & 4.67 & 10.84 & 9.37 & 4.67 & 10.79 & 9.33 \\
\hline $\operatorname{Sim} 4$ & $17.23^{*}$ & $36.85^{*}$ & $32.19^{*}$ & 17.56 & $34.74 *$ & $30.66^{*}$ & 4.60 & $10.48^{*}$ & $9.08^{*}$ & 4.58 & $9.96^{*}$ & $8.69 *$ \\
\hline Sim 5 & $12.13^{*}$ & $30.34 *$ & $26.01 *$ & $12.13 *$ & $30.34 *$ & $26.01 *$ & $3.56^{*}$ & $8.46^{*}$ & $7.30^{*}$ & $3.56^{*}$ & $8.46^{*}$ & $7.30 *$ \\
\hline Sim 6 & $16.21^{*}$ & $33.60^{*}$ & $29.47 *$ & $16.21 *$ & $33.60 *$ & $29.47 *$ & $4.20 *$ & $9.60 *$ & $8.32 *$ & $4.20 *$ & $9.60 *$ & $8.32 *$ \\
\hline $\operatorname{Sim} 7$ & $15.82 *$ & $32.49^{*}$ & $28.53^{*}$ & $16.02 *$ & $30.95 *$ & $27.40^{*}$ & $4.14 *$ & $9.31 *$ & $8.08^{*}$ & $4.11 *$ & $8.79 *$ & $7.68 *$ \\
\hline
\end{tabular}

(i) * the difference between to the base run's figure is statistically different from zero (at 5\%);

(ii) $\operatorname{Sim} 1=$ improved seeds; Sim2=mechanization; Sim3=crop extension services; Sim4=ASDP package; Sim5=2007 cereal prices; Sim6=2011 cereal prices; $\operatorname{Sim} 7=2011$ cereal prices \& ASDP

Source: Authors' estimations using TNPS-1 
Figure1: Non-parametric profit variation due to ASDP package in comparison to the base year, "smallholders" and "nonsmallholders” targeting profiles ${ }^{(i)}$

profit variation due to ASDP

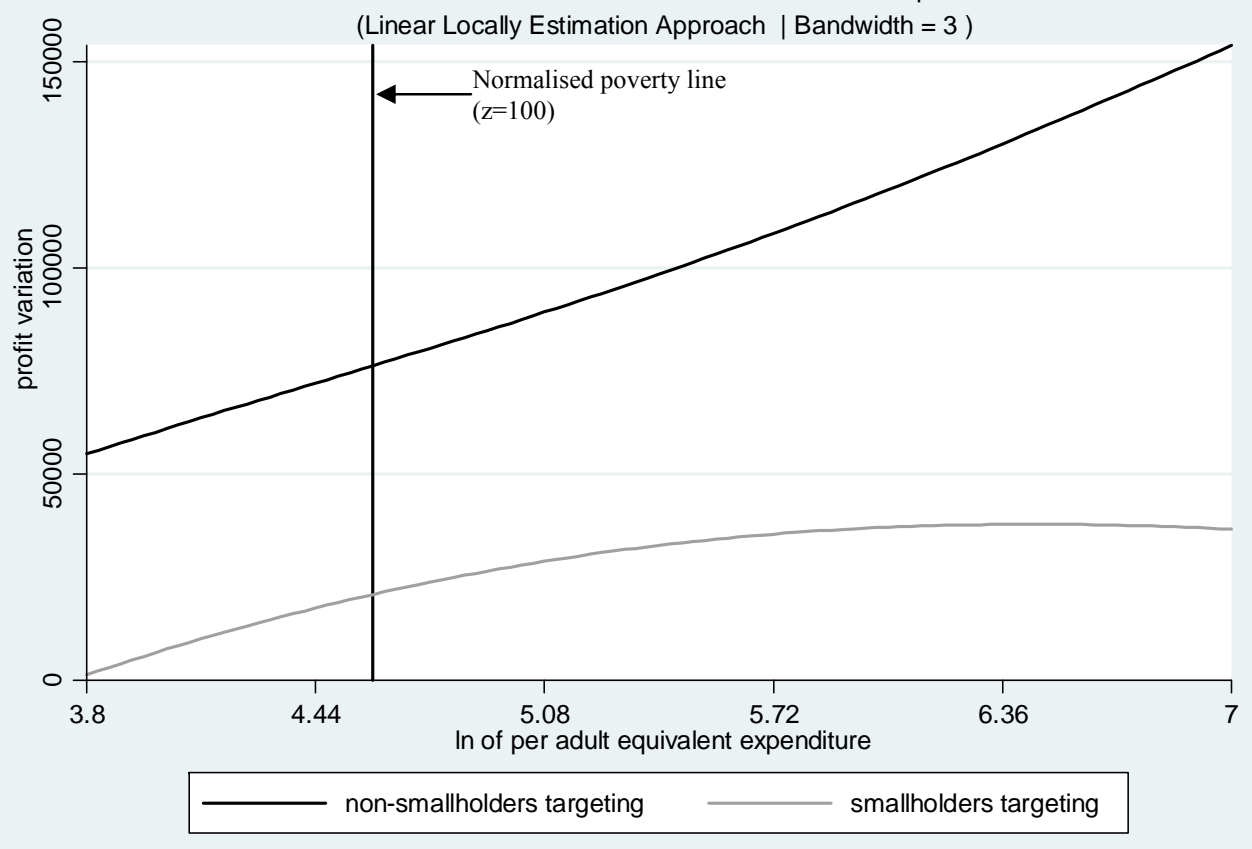

(i) Note: Poverty line is normalized to 100

Source: Authors' estimations using TNPS-1 
Figure2: Poverty (FGT0 and FGT1) curves under “pro-poor” and “non-smallholders” targeting profiles, different simulation scenarios ${ }^{(i)}$
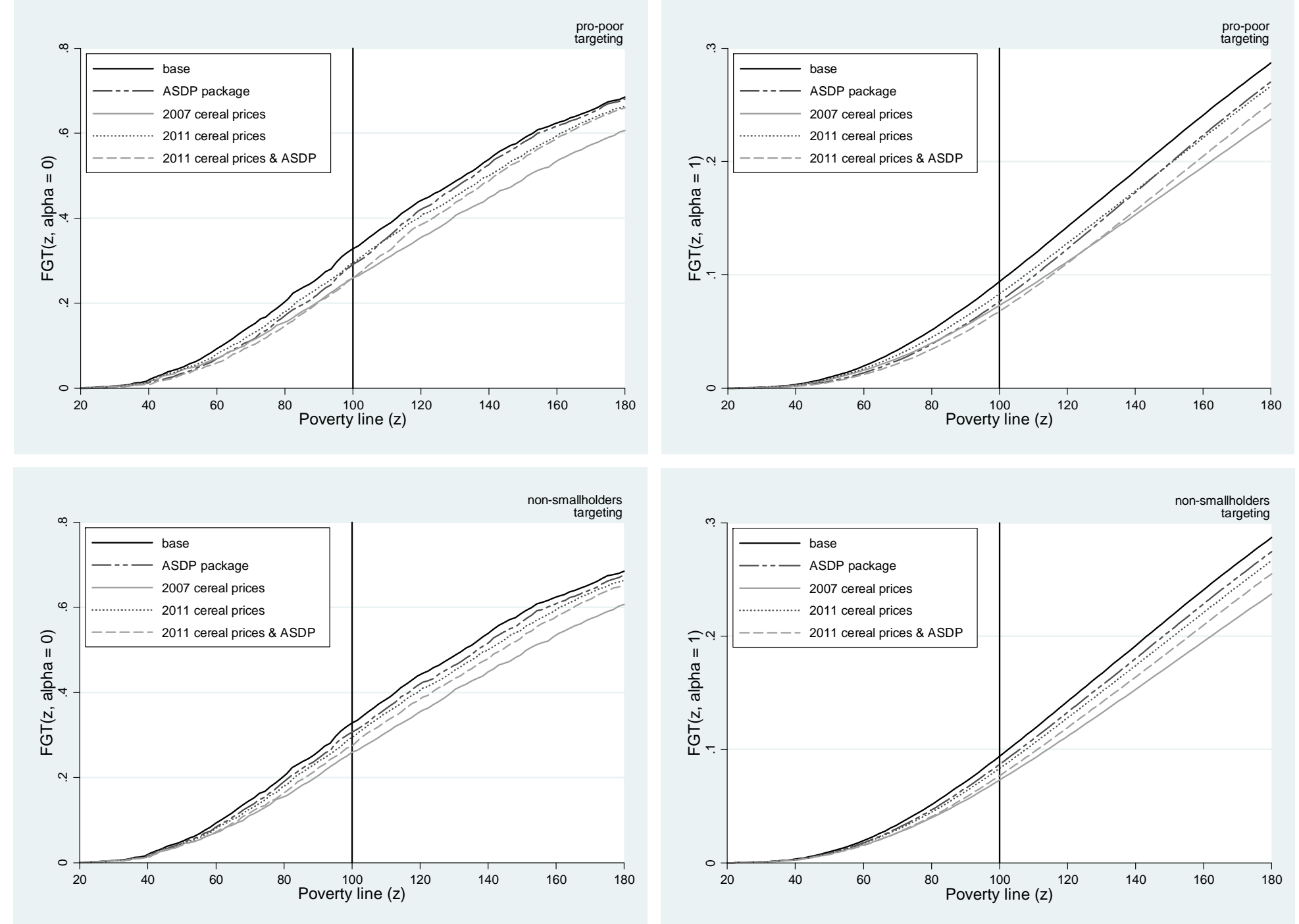

(i) Note: Poverty line is normalized to 100 Source: Authors' estimations using TNPS-1 


\section{Conclusions}

The original idea of this work stemmed out from evidence that a remarkable growth in aggregate agricultural output between the end of '90s and 2007 did not translate into significant poverty reduction and nutrition improvements for Tanzanian households. This is a surprising result considering the growing literature on the pro-poor nature of agricultural growth. Indeed, agricultural growth was driven by large-scale farmers and growth was unevenly distributed affecting only a few regions across the country.

A more compelling thrust to this study was the renewed interest towards agricultural development by the Tanzanian Government that has recently recognized the pivotal role of agriculture in reducing poverty and designed an Agricultural Sector Development Programme (ASDP). Referring to this, the relevant question is what would be the impacts in terms of poverty reduction should the ASDP be fully implemented. Specifically, which are the agricultural interventions featuring the largest potential in achieving the Government targets in terms of poverty reduction? How the ASDP should be implemented to be most effective in reducing poverty?

In order to answer to these research questions a non-separable agricultural household model was estimated to analyze households' production and consumption decisions under labour market failure. The models above are able to capture adjustments in production (both in output and input) and consumption behaviors resulting from specific policy interventions whose impacts are mimicked through simulations. Other studies simulating farm households' behaviour in presence of labour market failures focused on determinants of labour supply. Instead, this study, by taking into account the main features of Tanzanian rural economy, uses the estimates of the non-separable agricultural household model to assess the partial equilibrium impact of different agricultural policies and price changes on farm households' welfare.

The results of the production system highlight the characteristics of Tanzanian agriculture: the importance of land and household labour as productive factors, and the subsistence nature of farm production (with a considerable number of crops grown as a subsistence self-consumed crop featuring a low own-price elasticity). In addition, elasticity estimates show that agricultural outputs are complements in the agricultural system. The estimation of the demand system reveals that the diet among the poor is limited to quite a few food items.

Simulation results allow answering to the research questions above. Indeed, the estimation of the impact of the ASDP policies shows that agriculture can be very effective in reducing poverty. Among the agricultural policies included in the ASDP package, mechanization (i.e. ox-plough adoption) is the most effective single policy increasing farm profits and, as a result, reducing poverty. More importantly, to be more effective, agricultural policies should be designed and 
carried out by targeting the poor. Anyway, even without specific targeting, ASDP has a strong impact in reducing poverty. However, even with a pro-poor targeting, poverty reduction achievements fall short to the very ambitious targets set by the Tanzanian government.

Another important result emerging from simulations shows that a targeting oriented to those who have relatively more land results in a more effective poverty reduction. The reason for this is that land is indeed a limiting factor for smallholders, whose very low land endowment prevents the possibility of significantly increasing agricultural production and profit. This has two main policy implications: (i) there is a need, as recently recognized by the Tanzanian Government, for a new land reform facilitating the access to land for smallholders, and (ii) in absence of a land reform, if the policy objectives are the reduction in the overall poverty, it is better to target relatively larger farmer.

Finally, simulations show the very impressive impact of the recent food price crisis on households' welfare (ceteris paribus, food price crisis increased rural headcount ratio by about 7 percentage points). This result should call for a government intervention aiming at limiting food price movements.

In conclusion, this study shows that agriculture is effective in reducing poverty in Sub-Saharan Africa. However, better results could be obtained if sector-specific policies are complemented by other policies, such as a land reform aiming at facilitating the access to land for smallholders and price policies to reduce adverse price movements. From the modelling viewpoint, the agricultural household model proves effective in mimicking the actual operational conditions existing in Tanzanian agriculture and flexible enough to simulate a number of policy interventions. Of course, the results above, though interesting, are obtained in a partial equilibrium analysis framework and can be seen at best as an approximation to the overall general equilibrium impact of a given policy package. Anyway, in our opinion this study provides a robust tool for the analysis of the impact on households welfare of agricultural policies, as well as price changes, in a context like that of rural Tanzanian economy. 


\section{References}

Abdulai, A., Regmi, P.P., 2000. Estimating labor supply of farm households under non separability: empirical evidence from Nepal. Agricultural Economics. 22(3), 309-320.

Anríquez, G., Stamoulis, K., 2007. Rural Development and Poverty Reduction: Is Agriculture Still the Key? ESA FAO working paper 07-02.

Araar A., Duclos, J.Y., 2007. DASP: Distributive Analysis Stata Package, PEP, World Bank, UNDP and Université Laval.

Ball, V. E., 1988. Modeling Supply Response in a Multiproduct Framework. American Journal of Agricultural Economics. 70, 813-825.

Chang'a, L., 2009. Seasonal rainfall forecasting in Tanzania. Paper presented at the Workshop on High-Impact Weather Predictability and Information system for Africa and AMMATHORPEX Forecastor's Handbook. ICTP, Trieste, Italy, 5-8 October, 2009.

Christiaensen, L., Demery, L., 2007. Down to Earth: Agriculture and Poverty Reduction in Africa. World Bank, Washington DC.

Christiaensen, L., Hoffmann, V., Sarris, A., 2005. Coffee Price in Perspective: Household Vulnerability among Rural Coffee-Growing Smallholders in Rural Tanzania. Mimeo, World Bank, Washington, DC. Cited in Christiaensen L., Demery, L. (Eds), Down to Earth: Agriculture and Poverty Reduction in Africa. World Bank, Washington DC.

Colby, H., Xinshen, D., Agapi, S., 2000. Cross-Commodity Analysis of China's Grain Sector: Sources of Growth and Supply Response. U.S. Department of Agriculture, Economic Research Service, Market and Trade Economics Division. Technical Bulletin, 1884.

Davidson, R., Duclos, J.Y., 2000. Statistical Inference for Stochastic Dominance and for the Measurement of Poverty and Inequality. Econometrica. 68(6), 1435-1464.

Deaton, A.S., Muellbauer, J., 1980. An Almost Ideal Demand System. American Economic Review. 70(3), 312-26.

de Janvry, A., Fafchamps, M., Sadoulet, E., 1991. Peasant household behaviour with missing markets: Some Paradoxes Explained. Economic Journal. 101, 1400-1417.

de Janvry, A., Sadoulet, E., 2005. Access to Land and Development. Prepared as an entry for the New Palgrave Dictionary of Economics, second ed. Palgrave Macmillan.

Deininger, K., 2009. Moving towards pro-poor systems of land administration: Challenges for land and asset distribution in Africa. Agriculture for Development, Center of Evaluation for Global Action, UC Berkeley.

Dorward, A., Kydd, J., Morrison, J., Urey, I., 2004. A Policy Agenda for Pro-Poor Agricultural Growth. World Development. 32(1), 73-89.

Fafchamps, M., 1992. Cash Crop Production, Food Price Volatility and Rural Market Integration in the Third World. American Journal of Agricultural Economics. 74(1), 90-99.

FAO, 2011. Global Information and Early Warning System on Food and Agriculture (GIEWS) online dataset. http://www.fao.org/giews/. Accessed on December 2011.

$\mathrm{FAO} / \mathrm{WHO} / \mathrm{UNU}$, 1985. Report of a joint expert consultation: energy and protein requirements. Technical Report Series 724. WHO, Geneva.

Feder, G., Lau, L.J., Lin, J.Y., Luo, X., 1990. The Relationship between Credit and Productivity in Chinese Agriculture: A Microeconomic Model of Disequilibrium. American Journal of Agricultural Economics. 72(4), 1151-1157. 
Ferreira, F., Fruttero, A., Leite, P., Lucchetti, L., 2011. Rising Food Prices and Household Welfare: Evidence from Brazil in 2008. Journal of Agricultural Economics, forthcoming.

Fulginiti, L., Perrin, R., 1990. Argentine Agricultural Policy in a Multiple-Input, Multiple-Output Framework. American Journal of Agricultural Economics. 72, 279-288.

Gordon, H., 2008. Agricultural Productivity and Shared Growth. In: Utz, R. (Ed), Sustaining and Sharing Economic Growth in Tanzania. World Bank, Washington DC, pp. 97-141.

GoT (Government of Tanzania), 2011. Evaluation of the Performance and Achievements of the Agricultural Sector Development Programme (ASDP). Ministry of Agriculture, Food Security and Cooperatives, Dar es Salaam, Tanzania.

GoT (Government of Tanzania), 2010. 2008/2009 Year One National Panel Survey Integrated Households Survey. National Bureau of Statistics (NBS), Dar es Salaam, Tanzania.

GoT (Government of Tanzania), 2009. 2007 Household Budget Survey, National Bureau of Statistics (NBS), Dar es Salaam, Tanzania.

Haggblade, S., Hazell, P., Reardon, T., 2007. Transforming the Rural Non-Farm Economy: Opportunities and Threats in the Developing World. Johns Hopkins University Press, Baltimore.

Hazell, P., Haggblade, S., 1991. Rural-Urban Growth Linkages in India. Indian Journal of Agricultural Economics. 46(4), 515-529.

Henning, C.A., Henningsen, A., 2007a. Modeling Farm Households' Price Responses in the Presence of Transaction Costs and Heterogeneity in Labor Markets. American Journal of Agricultural Economics. 89(3), 665-681.

Henning, C.A., Henningsen, A., 2007b. AJAE Appendix: Modeling Farm Households' Price Responses in the Presence of Transaction Costs and Heterogeneity in Labor Markets. American Journal of Agricultural Economics Appendices. 89(3).

Jacoby, H., 1993. Shadow Wages and Peasant Family Labour Supply: An Econometric Application to the Peruvian Sierra. Review of Economic Studies. 60, 903-921.

Ligon, E., Sadoulet, E., 2007. Estimating the Effects of Aggregate Agricultural Growth on the Distribution of Expenditures. Background note for the World Development Report 2008, The World Bank, Washington DC.

Olson, D., Zoubi, T.A., 2011. Efficiency and Bank Profitability in MENA Countries. Emerging Markets Review. 12(2), 94-110.

Pauw, K., Thurlow, J., 2010. Agricultural growth, poverty, and nutrition in Tanzania. IFPRI discussion papers 947, International Food Policy Research Institute (IFPRI).

Ravallion, M., Datt, G., 1996. How Important to India's Poor is the Sectoral Composition of Economic Growth. World Bank Economic Review. 10(1), 1-26.

Skoufias, E., 1994. Using shadow wages to estimate labour supply of agricultural households. American Journal of Agricultural Economics. 76, 215-227.

Sidhu, S., Baanante, C., 1981. Estimating Farm-Level Input Demand and Wheat Supply in the Indian Punjab Using a Translog Profit Function. American Journal of Agricultural Economics. 63, 237-246.

Singh, I., Squire, L., Strauss., J., 1986. Agricultural Household Models - Extensions, Applications and Policy. The Johns Hopkins University Press, Baltimore. 
Taylor, J.E., Adelman, I., 2003. Agricultural household models: Genesis, evolution and extensions. Review of Economics of the Household. 1(1), 33-58.

World Bank, 2011. World development indicators. www.worldbank.org. Accessed December 2011. World Bank: Washington DC. 


\section{Appendix A - Empirical Specification and Estimation Strategy}

As noted in section 2.2, the econometric estimation of the model requires a two-stage estimation strategy, since shadow wage cannot be directly observed (Henning and Henningsen, 2007a and 2007b). Thus, at the first stage we estimated the shadow prices of family labour for adult males and females, and in the second stage we estimated the production system (profit and netput share functions) and the demand system. This approach also allows fairly robustly overcoming the complexity of simultaneous estimation of the consumption and production functions under labour market failure.

\section{a) Shadow Wage}

The Cobb-Douglas production function is specified as follows (Jakoby, 1993; Abdulai and Regmi, 2000):

$$
\ln Y_{i}=\sum_{j=1}^{n} \alpha_{j} \ln Z_{i j}+\sum_{k=1}^{m} \gamma_{k} d_{i k}+\varepsilon_{i}
$$

where $Y_{i}$ represents the total value of agricultural output produced by farm household $i, Z_{i j}$ is a vector representing the quantity of input $j$ used by farmer $i, d_{k}$ is a vector of location dummies. The inputs represented by vector $Z_{j}$ are total land area, quantity of pesticides, quantity of inorganic fertilizers, quantity of organic fertilizers, days of hired male labour, days of hired female labour, days of family adult male labour, days of family adult female labour, the value of mechanization, an index for plots irrigation and an index of land quality. In addition, the age, sex and level of education of household head were also included as proxies for management input. Finally, the distance of plots from principal roads and markets is included ${ }^{30}$.

Since input variables are expected to be endogenous regressors, instrumental variables (IV) were used to estimate the Cobb-Douglas production function.

Once A.1 was estimated, the shadow daily wage rate associated to family male and female labour were derived as follows:

$$
\hat{w}_{i}=\frac{\hat{\alpha}_{j} \hat{Y}}{L_{i}}, \mathrm{i}=1,2
$$

where $\hat{Y}$ is the predicted value of output derived from the estimated coefficient $\hat{\alpha}_{j} . L_{1}, L_{2}$ and $L_{3}$ are the total daily hours of labour by adult males and females, respectively.

Finally, a test of equality between marginal products of labour and the market wages has been carried out. As noted by Abdulai and Regmi (2000, p.318), "under the assumption that households

\footnotetext{
${ }^{30}$ In the regression all variable inputs are in logarithmic form. Given the presence of zero values in all inputs, except land, we added one to all inputs' value and then transformed into logarithm.
} 
maximize their utility, the effective wage received by family members participating in the off-farm labour market should be equal to the marginal productivity of on-farm family labour" (i.e. the shadow wage). Assuming there are no transaction costs in working off-farm, the effective wage should be equal to the market wage. In order to test the equality of marginal productivity and wage rate we followed Jacoby (1993), by estimating the following regression

$$
\hat{W}_{i}=\hat{a}+\hat{b} W_{i}+u_{i}, \quad i=1,2
$$

where $\hat{W}_{i}$ is the estimated shadow daily wage rate of adult male and female labour, $W_{i}$ is the daily wage rate received by market workers, and $u_{i}$ is a random term including measurement error.

According to Abdulai and Regmi (2000, p.318), "utility maximization and efficiency of the labour market then imply that $\hat{a}=0$ and $\hat{b}=1$. This means that the allocation of time between farm and market is made purely on efficiency grounds."

\section{b) Farm Production System}

Following the empirical procedure proposed by Sidhu and Baanante (1981), a translog profit function was estimated in order to obtain the full coefficients of the profit function as well as input and output elasticities.

The profit function is written as

$$
\begin{aligned}
& \ln \pi_{c, h}=a_{0}+\sum_{i=1} a_{i} \ln p_{i, c}+\sum_{m=1} b_{m} \ln Z_{m, h}+\frac{1}{2} \sum_{i, j} b_{i j} \ln p_{i, c} \ln p_{j, c}+ \\
& +\frac{1}{2} \sum_{m, n} c_{m n} \ln Z_{m, h} \ln Z_{n, h}+\sum_{i, m} d_{i m} \ln p_{i, c} \ln Z_{m, h}+\varepsilon_{i, h}
\end{aligned}
$$

with the following constraints:

$$
b_{i j}=b_{j i} ; c_{m n}=c_{n m} ; \sum_{i} a_{i}=1 ; \sum_{m} b_{m}=1 ; \sum_{i} b_{i j}=\sum_{m} c_{m n}=\sum_{i} d_{i m}=0
$$

where $\pi_{c, h}$ is the profit of household $h$, living in $\operatorname{cluster}^{31} c, p_{i, c}$ is the median price of output or input $i$ in cluster $j, Z_{m, h}$ is the fixed input $m$ used by the household $h$ and $\varepsilon_{i, h}$ is the residual term. The same properties (namely, symmetry and homogeneity) can be written in terms of elasticities. In order to have them respected it was necessary to run the system's estimation on households with non-negative profit only (or, whose sum of profit shares was not lower than zero).

\footnotetext{
${ }^{31}$ To take into account regional differences in prices, we constructed clusters as a combination of regions, urban-rural location and districts, which resulted in 173 clusters.
} 
As for the estimation procedure, the first step was to associate every crop cultivated in the 2008 long rainy ${ }^{32}$ season $^{33}$ (masika) to a specific category of goods. All crops cultivated in the 2008 long rainy season were grouped in two categories: cereals (including maize, which account for 60 percent of the value of this category on profit, rice, sorghum, millet and wheat), other crops (including tubers and roots, legumes, oil, fruits, vegetables and cash crops) ${ }^{34}$.

Fertilizers (organic and inorganic) and pesticides, hired labour and family labour are the three categories identifying the variable inputs. Thus, the expenditure in fertilizers and pesticides, household labour (calculated multiplying the days of labour times the daily shadow wage for adult males and females) and hired labour were computed and input shares calculated for the production system. Land, measured as hectares cultivated by farms, and irrigation, i.e. area-weighted average number of irrigations, were considered as fixed inputs within the seasonal observation interval.

From equation (A.4), using the Hotelling's lemma, we obtain the share equations $S_{i}$ :

$$
S_{i}=\frac{\partial \ln \pi}{\partial \ln p_{i}}=\frac{p_{i} Y_{i}}{\pi}
$$

that are linear in normalized prices:

$$
S_{i}=a_{i}+\sum_{j=1} b_{i j} \ln p_{j}+c_{i} \ln Z
$$

However, since the input and output shares sum to unity, one input or output equation is dropped from the system to avoid singularity problems. Thus, in the production system there are one output category (cereals, $S_{l}$ ) and three input categories (fertilizers and pesticides, household labour, hired labour, $S_{2}, S_{3}$ and $S_{4}$, respectively).

The dropped profit share equation is that of other crops, whose coefficients are obtained by using the adding-up property. The various symmetry and homogeneity constraints were imposed during the estimation.

Profit and profit shares functions were estimated simultaneously, by imposing the equality between the coefficients in the shares equations (in A.6) and those in the profit equation (A.4). The simultaneous estimation allows to satisfy, among other things, the assumption of profit maximization.

Four additional dummy variables were added in the profit function to capture the effect of other factors on production and to allow to carry out additional simulation. These are the use of improved

\footnotetext{
${ }^{32}$ It should be noted that a quite severe drought occurred during the 2008/2009 season, particularly in the Northern part of Tanzania (Chang'a, 2009).

${ }^{33}$ The reference period for farm production is the 2008 long rainy season, both for crops cultivated and input used. Data regarding the short rainy season (vuli) were not included in the empirical analysis since too few households cultivate during this season, implying the presence of too many missing values in the production system.

${ }^{34}$ This classification is determined by mapping the categories in the underlying micro data and then aggregating accordingly the commodities.
} 
seeds, ownership of ox-plough, household head's education (literate or not) and access to agricultural extension services.

As suggested in Sidhu and Baanante (1981), the system of the profit and profit shares' equations was estimated through the seemingly unrelated regression (SUR) approach.

From A.5 and A.6, output supply and input demand elasticities to own price are calculated as

$$
\eta_{i i}=\frac{\beta_{i i}}{s_{i}}+s_{i}-1
$$

and cross price elasticities are:

$$
\eta_{i j}=\frac{\beta_{i j}}{s_{i}}+s_{j}
$$

\section{c) Household Consumption Decisions}

On the consumption side, an Almost Ideal Demand System (AID System) as proposed by Deaton and Muellbauer (1980) was used to estimate the impact of changes in prices and income on households' consumption behaviour and the equivalent gains following the simulations proposed in this study.

The AID System-associated demand functions are derived as budget share as follows:

$$
w_{j, c, h}=a_{j}+\sum_{k=1}^{K} b_{j, k} \ln p_{k, c}+c_{j} \ln \frac{x_{c, h}}{z\left(p_{c}\right)}+e_{j} D_{c, h}+\varepsilon_{j, h}
$$

with the following constraints:

$$
\sum_{j=1}^{J} a_{j}=1 ; \sum_{j=1}^{J} b_{j k}=0 ; \sum_{j=1}^{J} c_{j}=0 ; \sum_{j=1}^{J} e_{j}=0 ; b_{j k}=b_{k j}
$$

where $w_{j, c, h}$ is the budget share by the household $h$ living in cluster $c$ associated to the category $j$ and $p_{k, c}$ is the weighted median price of category $k$ in cluster $c, x_{c, h}$ is the per-adult equivalent household's total expenditure, $z_{c}$ is the poverty line in cluster $c, D_{c, h}$ is a vector of sociodemographic characteristics of households, and $\varepsilon_{j, h}$ is the residual term.

We grouped households' expenditure in 13 categories of goods, i.e. 11 food categories, leisure $^{35}$ and a non-food category. Food categories are: maize; other cereals; starches; sugar and

\footnotetext{
${ }^{35}$ The amount of leisure was determined by calculating the yearly available time of households minus time spent in labour activities. It is assumed that each household member between 15 years and 60 years has 12 hours per day, each household member between 5 years and 14 years has 6 hours per day, and each household member older than 60 years has 6 hours per day available for work and/or leisure. The annual available time of the household is calculated by multiplying the total hours per day of all household members by 365 . Time spent in labour activities comprises on-farm labour, other self-employment jobs, wage jobs and unpaid family activities. To estimate the value of leisure, the hourly shadow wage rate in agricultural activities was multiplied by the hours of leisure per day.
} 
sweets; pulses, dry, nuts and seeds; vegetables and fruits; meat, eggs and dairy; fish; oil and fats; salt and spices; beverages ${ }^{36}$.

The AID-System was then estimated as specified by equation (A.9), in which budget shares are linear in $b_{j k}, c_{j}$ and $e_{j}$. The spatial variability of prices in Tanzania was taken into account. A threestage least squares (3SLS) estimator was used to account for the possible endogeneity of $y_{c, h}$ and the shadow wage and to allow for contemporaneous correlation with the disturbance terms. Indeed, food consumption decisions are not completely independent and linear equations have correlated error terms.

The adding-up property of the demand system requires that one of the expenditure share equations be dropped from the system to avoid singularity problems. The dropped expenditure share equation is non-food, whose coefficients are obtained by using the adding-up property. Symmetry and the various homogeneity constraints were imposed in the estimation of the system of equations.

At this point, it is possible to derive the consumption in real terms as

$$
\ln e_{c h}=b\left(p_{r}\right)\left[\frac{\ln x_{c h}-\ln z\left(p_{c}\right)}{b\left(p_{c}\right)}\right]+\ln z\left(p_{r}\right)
$$

where $e_{c h}$ is what Kings (1983) defined the "equivalent income" and $z\left(p_{c}\right)$ and $b(p)$ are defined as

$$
\ln z\left(p_{c}\right)=a_{0 c}+\sum_{k=1}^{K} a_{k} \ln p_{c k}+\frac{1}{2} \sum_{j=1}^{J} \sum_{k=1}^{K} b_{j k} \ln p_{c j} \ln p_{c k}
$$

which can be approximated by the poverty $\operatorname{line}^{37}$ in strata $c$, and $b(p)$ is a price index

$$
b(p)=\prod_{j} p_{j}^{c_{j}}
$$

The own price elasticity $\left(\varepsilon_{j j}\right)$ for $j$-th good is

$$
\varepsilon_{j j}=\left(\frac{b_{j j}}{\bar{w}_{j}}\right)-c_{j}-1
$$

The cross price elasticity $\left(\varepsilon_{j k}\right.$ ) of good $j$ with respect to good $k$ 's price is

$$
\varepsilon_{j k}=\frac{b_{j k}}{\bar{w}_{j}}-\frac{c_{j}}{\bar{w}_{j}} \bar{w}_{j}
$$

The income elasticity $(\eta j)$ is

\footnotetext{
${ }^{36}$ Total consumption values in the household survey were converted to an annual basis when required. In addition, individual consumptions per adult equivalent were calculated by using the "caloric requirements" approach to determine equivalence scales, with data from FAO/WHO (1985).

${ }^{37}$ Since there is not an official poverty line for 2008/2009, we used the official basic needs poverty line reported for 2007 (reported in GoT, 2009) deflated by the inflation rate for 2008 and 2009 reported in Tanzania National Panel Survey Report, Round 1.
} 


$$
\eta_{j}=\frac{c_{j}}{\bar{w}_{j}}+1
$$

\section{Appendix B - Estimation of policy impacts on poverty}

Poverty analysis was finally carried out to estimate the impact on households' welfare due to agricultural policies and prices changes, which affect both production and consumption behaviours.

The standard Foster-Greer-Thorbecke (1984) (FGT) measures of monetary poverty (headcount ratio and poverty gap) were calculated for the base scenario (i.e. the scenario without simulations) and for each simulation scenario. Absolute changes in household income are fully transmitted to household consumption with the hypothesis that there is no change in savings.

The FGT indices can be formalized as

$$
P_{\alpha}(z)=\frac{1}{N} \sum_{h=1}^{H} \rho_{c, h} n_{c, h}\left(\frac{z-e_{h}}{z}\right)^{\alpha}
$$

where $N$ is the number of the households in the survey, $n_{h, c}$ is the size of the household $h$ in cluster $c, \rho_{h}$ is the sampling weight of $h$ in cluster $c, z$ is the real poverty line estimated in terms of reference prices and $e_{h}$ is the equivalent consumption as in equation (A.10), and $\alpha$ measures the distribution sensitivity of the poverty index. According to different values of $\alpha, P_{\alpha}(z)$ gives different measures of poverty: among those presented in this paper, $P_{0}(z)$ measures the incidence of poverty (headcount ratio (HCR)) and $P_{1}(z)$ measures the depth of poverty (poverty gap).

The equivalent income after simulation $t$ will then be:

$$
\ln e_{c h}^{t}=b\left(p_{r}\right)\left[\frac{\ln \left(x_{c h}^{t}\right)-\ln z\left(p_{c}^{t}\right)}{b\left(p_{c}^{t}\right)}\right]+\ln z\left(p_{r}\right)
$$

where $\ln \left(x_{c h}^{t}\right)=\ln \left(x_{c h}^{0}+\Delta \pi_{c h}^{t}\right)$ with $\Delta \pi(a e)$ being the profit variation (per adult equivalent) and $x_{c h}^{0}$ is the nominal expenditure (per adult equivalent) at the base-year.

Therefore, the potential impact on poverty of a policy change can be measured as

$$
\Delta P_{\alpha}(z)=\frac{1}{N}\left(\sum_{h=1}^{H} \rho_{c, h} n_{c, h}\left(\frac{z-e_{c h}^{t}}{z}\right)^{\alpha}-\sum_{h=1}^{H} \rho_{c, h} n_{c, h}\left(\frac{z-e_{c h}^{o}}{z}\right)^{\alpha}\right)
$$

where $e_{c h}^{o}$ and $e_{c h}^{t}$ are the equivalent consumption pre and post policy change, respectively.

From the literature on stochastic dominance analysis (Davidson and Duclos, 2000), we know that if $\Delta P^{s}(z)=P^{t=1, . . T}(z ; s)-P^{t=0}(z ; s)<0$ for any choice of poverty index within a class of ethical order $\mathrm{s}=\alpha+1$ and for any poverty line within $\left[0, z^{+}\right]$, then we can unambiguously affirm that the simulated scenario $t=1, . ., T$ is poverty decreasing with respect to the base year $(t=0)$. In such a case, 
the distribution under the policy scenario is said to stochastically dominate the distribution at the base year. If $\Delta P^{\mathrm{s}}(z)$ switches sign (i.e. positive or equal to zero) for some poverty thresholds within $\left[0, z^{+}\right]$, then the conclusions are ambiguous and some caution should be used in interpreting a scenario's effectiveness on poverty change. 


\section{Appendix C - List of Variables}

Table C.1 Definitions, means and standard deviations of variables used in main empirical specifications

\begin{tabular}{|c|c|c|c|}
\hline Variable Name & Definition & Mean & Std. Dev. \\
\hline loutput_value ${ }^{(*)}$ & log of output value & 11.71 & 1.37 \\
\hline lhh_land ${ }^{(*)}$ & $\log$ of land area (acres) & 1.51 & 0.74 \\
\hline lhh_pesticides ${ }^{(*)}(!)$ & $\log$ of quantity of pesticides used & 0.21 & 0.73 \\
\hline 1hh_inorganic_fert ${ }^{(*) !()}$ & $\log$ of quantity of inorganic fertilizers used & 0.57 & 1.50 \\
\hline 1hh_organic_fert ${ }^{(*)(!)}$ & $\log$ of quantity of organic fertilizers used & 1.04 & 2.35 \\
\hline lhh_tot_lab_f $\mathrm{f}^{(*)(!)}$ & $\log$ of quantity of female family labour (days) & 3.82 & 1.50 \\
\hline lhh_tot_lab_m $\mathrm{m}^{(*)(!)}$ & $\log$ of quantity of male family labour (days) & 3.45 & 1.86 \\
\hline lhired_female ${ }^{(*)(!)}$ & $\log$ of quantity of female hired labour (days) & 0.96 & 1.40 \\
\hline 1hired_male ${ }^{(*)(!)}$ & $\log$ of quantity of male hired labour (days) & 0.65 & 1.20 \\
\hline hhhead_age ${ }^{(*)}$ & hh head age (years) & 47.50 & 15.52 \\
\hline hhhead_age ${ }^{2(*)}$ & hh head age squared (years) & 2524.59 & 1622.61 \\
\hline hhhead_sex ${ }^{(*)}$ & dummy: 1 if hh head is male & 0.75 & 0.43 \\
\hline primary & dummy: 1 if hh head has primary education as highest grade completed & 0.64 & 0.48 \\
\hline secondary_plus & dummy: 1 if hh head has secondary education or more as highest grade completed & 0.07 & 0.26 \\
\hline land_quality ${ }^{(*)}$ & average of quality index of total household's plots ( $1=$ bad; $2=$ average; $3=$ good $)$ & 2.46 & 0.53 \\
\hline irrigation $^{(*)}$ & average of dummy irrigation of total household's plots (1=irrigated) & 0.03 & 0.16 \\
\hline $\operatorname{lroad}(*)(!)$ & distance to road $(\mathrm{km})$ & 0.84 & 0.66 \\
\hline lmarket ${ }^{*(!)}$ & distance to market $(\mathrm{km})$ & 1.75 & 0.87 \\
\hline agr_zone $1^{(*)}$ & agro-region dummy variable ( 1 if agro-region $1{ }^{(\mathrm{i})} ; 0$ otherwise) & 0.28 & 0.45 \\
\hline agr_zone $2^{(*)}$ & agro-region dummy variable ( 1 if agro-region $2 ; 0$ otherwise) & 0.32 & 0.47 \\
\hline agr_zone $3^{(*)}$ & agro-region dummy variable ( 1 if agro-region $3 ; 0$ otherwise) & 0.20 & 0.40 \\
\hline agr_zone $4^{(*)}$ & agro-region dummy variable ( 1 if agro-region 4; 0 otherwise) & 0.15 & 0.35 \\
\hline urban & Dummy variable ( 1 if household lives in urban areas; 0 otherwise) & 0.37 & 0.48 \\
\hline hhhead_age_class 1 & dummy variable ( 1 if household head $<36 ; 0$ otherwise) & 0.22 & 0.42 \\
\hline hhhead_age_class 2 & dummy variable ( 1 if household head $>35$ and $<46$; 0 otherwise) & 0.27 & 0.44 \\
\hline hhhead_age_class 3 & dummy variable ( 1 if household head $>45$ and $<61 ; 0$ otherwise) & 0.32 & 0.47 \\
\hline hhhead_age_class 4 & dummy variable ( 1 if household head $>60 ; 0$ otherwise) & 0.19 & 0.39 \\
\hline Imechanization $^{(*)(!)}$ & $\log$ of value of agricultural mechanization & 9.07 & 2.28 \\
\hline $\mathrm{S}_{1}-$ production $^{(*)}$ & Share of the value of cereals produced on profit & 3.12 & 46.78 \\
\hline $\mathrm{S}_{2}-$ production $^{(*)}$ & Share of the value of fertilizers and pesticides used on profit & -0.68 & 5.66 \\
\hline $\mathrm{S}_{3}-$ production $^{(*)}$ & Share of the value of household labour used on profit & -2.42 & 49.65 \\
\hline $\mathrm{S}_{4}-$ production $^{(*)}$ & Share of the value of hired labour used on profit & -0.80 & 13.79 \\
\hline $\mathrm{S}_{5}-\operatorname{production}^{(*)}$ & Share of the value of other crops produced on profit & 1.30 & 12.07 \\
\hline $\mathrm{S}_{1}$ - consumption & Share of the value of maize consumed on total expenditure & 0.10 & 0.12 \\
\hline $\mathrm{S}_{2}-$ consumption & Share of the value of other cereals consumed on total expenditure & 0.10 & 0.10 \\
\hline $\mathrm{S}_{3}-$ consumption & Share of the value of starches consumed on total expenditure & 0.08 & 0.11 \\
\hline $\mathrm{S}_{4}-$ consumption & Share of the value of sugar and sweets consumed on total expenditure & 0.03 & 0.03 \\
\hline
\end{tabular}


$\mathrm{S}_{5}-$ consumption

$\mathrm{S}_{6}-$ consumption

$\mathrm{S}_{7}$ - consumption

$\mathrm{S}_{8}-$ consumption

$\mathrm{S}_{9}$ - consumption

$\mathrm{S}_{10}-$ consumption

$\mathrm{S}_{11}-$ consumption

$\mathrm{S}_{12}-$ consumption

$\mathrm{S}_{13}-$ consumption

$\ln \mathrm{P}_{1}$ - production $^{(*)(!)}$

$\ln \mathrm{P}_{2}$ - production $^{(*)(!)}$

$\ln \mathrm{P}_{3}$ - production $^{(*)(!)}$

$\ln \mathrm{P}_{4}$ - production $^{(*)(!)}$

$\ln \mathrm{P}_{5}$ - production $^{(*)(!)}$

$\ln \mathrm{P}_{1}$ - consumption

$\ln \mathrm{P}_{2}-$ consumption

$\ln \mathrm{P}_{3}-$ consumption

$\ln \mathrm{P}_{4}$ - consumption

$\ln \mathrm{P}_{5}$ - consumption

$\ln \mathrm{P}_{6}-$ consumption

$\ln \mathrm{P}_{7}$ - consumption

$\ln \mathrm{P}_{8}-$ consumption

$\ln \mathrm{P}_{9}-$ consumption

$\ln \mathrm{P}_{10}$ - consumption

$\ln \mathrm{P}_{11}-$ consumption

$\ln \mathrm{P}_{12}$ - consumption

$\ln \mathrm{P}_{13}-$ consumption

$\mathrm{ox}^{(*)}$

extension $^{(*)}$

literate $^{(*)}$

irrigation $^{(*)(!)}$

children $^{(*)}$

$\operatorname{lnhhsize} \mathrm{e}^{(*)}$

ln_profit

ln_y_equiv $\operatorname{improved}^{(*)}$
Share of the value of pulses, dry, nuts and seeds consumed on total expenditure

0.07

Share of the value of vegetables and fruits consumed on total expenditure

Share of the value of meat, eggs and dairy consumed on total expenditure

Share of the value of fish consumed on total expenditure

Share of the value of oil and fats consumed on total expenditure

Share of the value of salt and spices consumed on total expenditure

Share of the value of beverages consumed on total expenditure

Share of the value of leisure on total expenditure

Share of the value of non-food expenditure on total expenditure

Price of cereals

Price of fertilizers and pesticides

Price of household labour

Price of hired labour

Price of hired labour

Price of maize consumed on total expenditure

Price of other cereals consumed on total expenditure

Price of starches consumed

Price of sugar and sweets consumed

Price of pulses, dry, nuts and seeds consumed

Price of vegetables and fruits consumed

Price of meat, eggs and dairy consumed

Price of fish consumed

Price of oil and fats consumed

Price of salt and spices consumed

Price of beverages consumed on total expenditure

Price of leisure

Price of non-food expenditure

dummy variable ( 1 if household owns at least ox-plough; 0 otherwise)

dummy variable ( 1 if household receives extension services; 0 otherwise)

dummy variable ( 1 if household uses improved seeds; 0 otherwise)

dummy variable ( 1 if household head is literate; 0 otherwise)

average of dummy irrigation of total household's plots ( $1=$ irrigated) weighted by land acres

number of children per household

$\log$ of household size

$\log$ of absolute value of household profit

log of per adult expenditure (including the value of leisure) deflated by poverty line

0.08
0.08

0.08

$0.07 \quad 0.10$

$0.04 \quad 0.06$

$0.02 \quad 0.03$

$0.01 \quad 0.01$

$0.04 \quad 0.07$

$0.13 \quad 0.20$

$0.24 \quad 0.15$

$5.52 \quad 0.43$

$6.32 \quad 2.46$

$5.27 \quad 0.84$

$7.68 \quad 0.51$

$5.98 \quad 0.50$

$6.18 \quad 0.61$

$7.12 \quad 0.12$

$6.12 \quad 0.30$

$\begin{array}{ll}7.31 & 0.19\end{array}$

$\begin{array}{ll}7.25 & 0.19\end{array}$

$6.65 \quad 0.29$

$7.90 \quad 0.24$

$\begin{array}{ll}7.76 & 0.27\end{array}$

$7.73 \quad 0.18$

$6.67 \quad 0.31$

$8.50 \quad 0.46$

$3.36 \quad 1.50$

$7.34 \quad 0.28$

$0.08 \quad 0.26$

$0.23 \quad 0.42$

$0.18 \quad 0.38$

$0.72 \quad 0.45$

$1.02 \quad 0.13$

$2.20 \quad 1.91$

$1.46 \quad 0.62$

$11.23 \quad 1.59$

${ }^{(*)}$ refers to farm households only

(!) Given the presence of zero values we added one to the logarithmic transformation

(i) agro-region1: Dodoma, Tanga, Morogoro, Dar es Salaam, Zanzibar, Pemba; agro-region2: Arusha, Kilimanjaro, Kigoma, Shinyanga, Kagera, Mwanza,Mara; agro-region3: Mbeya, Singida, Tabora, Rukwa; agro-region4: Lindi, Mtwara, Ruvuma, Iringa

Source: Authors' calculations using TNPS-1 